\title{
PRÁTICA DE ENSINO DESENVOLVIDA NA DISCIPLINA DE GEOMORFOLOGIA COM USO DO GOOGLE EARTH ENQUANTO RECURSO DIDÁTICO
}

\author{
Lísia Moreira Cruz ${ }^{\text {(a) }}$ Anna Carolina Barcelos ${ }^{(b)}$ Silvio Carlos Rodrigues ${ }^{(c)}$
}

\footnotetext{
(a) Insituto de Geografia/Universidade Federal de Uberlândia, E-mail: lisia_mc@yahoo.com.br

(b) Insituto de Geografia/Universidade Federal de Uberlândia, E-mail: barceloscarolina @ hotmail.com

(c) Insituto de Geografia/Universidade Federal de Uberlândia, E-mail: silgel@ufu.br
}

EIXO: GEOGRAFIA FÍSICA - CURRÍCULO, FORMAÇÃO E PRÁTICAS DE ENSINO

\begin{abstract}
Resumo
O ensino de Geomorfologia por meio do emprego de diferentes linguagens, especialmente as ligadas às tecnologias, é uma estratégia que possibilita o enriquecimento das aulas. Nesse contexto, o objetivo do presente trabalho é abordar uso do Google Earth enquanto recurso didático, na disciplina de Geomorfologia, por meio de aplicação de atividade com o tema: Índice de Hack para identificação de setores anômalos e rupturas do relevo, junto aos alunos do curso de Geografia da Universidade Federal de Uberlândia. Verficou-se que esta prática constituiu uma interessante possibilidade uma vez que, o uso do Google Earth enquanto recurso didático se mostrou eficiente diante do objetivo proposto.
\end{abstract}

Palavras chave: Ensino de Geomorfologia; Ferramenta didática; Google Earth.

\section{Introdução}

A Geomorfologia é uma ciência complexa, dinâmica, e seu ensino demanda, além de conhecimentos específicos, o uso de estratégias que facilitem esse processo, para que a compreensão das formas, processos e gênese do relevo aconteça plenamente. Para a compreensão do relevo, acredita-se que haja necessidade de evocar ideias que façam a ligação do raciocínio conceitual com a realidade, assim como apontam as pesquisas de Souza (2009), Bertolini (2010), Oliveira (2010) e Afonso (2015). Assim, a construção mental acerca dos conteúdos geomorfológicos exige substancial esforço dos estudantes, que precisam associar conceitos, deduzir consequências e abstrair processos dinâmicos. Desse modo, no ensino da Geomorfologia a utilização das diferentes linguagens, especialmente as ligadas às tecnologias, é uma estratégia que possibilita o enriquecimento das aulas, colaborando para a sensibilização das relações existentes entre os conceitos geomorfológicos a sociedade e a natureza.

O uso de computadores capazes de executar, softwares, imagens, sons, animações, textos, permitem uma aprendizagem mais participativa e colaborativa. Quando conectados à internet as possibilidades se multiplicam. Nesse contexto os estudantes têm mais possibilidades e podem assimilar mais facilmente $o$ 
uso de recursos didáticos tecnológicos. (MORAN, 2000; OKADA, 2007). Partindo deste entendimento, o Google Earth apresenta-se como interessante instrumento de ensino, uma vez que, trata-se de um software que oferece diversas ferramentas que possibilitam avançar na compreensão dos aspectos geomorfológicos.

Ainda considerando a perspectiva do avanço no ensino de Geomorfologia, é possível abordar conteúdos mais específicos, em que sua aborgem no âmbito da sala de aula, pode ser enriquecida com uso dos recursos didáticos. Investigações relacionadas às drenagens fluviais, por exemplo, têm importante finalidade na Geomorfologia, associadas à compreensão da rede hidrográfica favorecem a apreensão e esclarecimento de questões geomorfológicas, uma vez que, os cursos d'água são agentes morfogenéticos muito ativos na esculturação da paisagem terrestre. (CHRISTOFOLETTI, 1980). Nesse aspecto, o uso do Google Earth, enquanto ferramenta didática mostra-se como valorosa alternativa.

Um número importante de trabalhos é dedicado ao uso do Google Earth como ferramenta de ensino na Geografia, no entanto, quase em sua totalidade, esses trabalhos são dedicados a experiências com Google Earth na educação básica. Diante do exposto, o presente trabalho tem como objetivo abordar uso do Google Earth enquanto recusos didático por meio de aplicação de atividade com o tema: Índice de Hack para identificação de setores anômalos e rupturas do relevo, junto aos alunos da disciplina de Geomorfologia do $2^{\circ}$ Período (diurno e noturno) do curso de Geografia da Universidade Federal de Uberlândia (Campus Uberlândia) no $2^{\circ}$ semestre de 2016. Espera-se assim gerar contribuições que possam ser aplicadas por professores, acessadas por alunos que se interessem pelo tema e também fornecer uma contribuição para que os professores elaborem outras atividades de acordo com as suas demandas.

\section{Ensino de Geomorfologia com uso de recursos didáticos: aplicações do Google Earth}

Os recursos didáticos, sendo um dos elementos a serem considerados nas práticas pedagógicas, juntamente com as dimensões humana e política do ensino, adquirem relevância em estudos recentes, principalmente relacionados às novas tecnologias difundidas no século XXI. A Geomorfologia é uma das disciplinas que mais se beneficia da tecnologia e atualmente dispõem de uma grande variedade de métodos, técnicas, e equipamentos que permitem estudar com profundidade formas de relevo e processos geomorfológicos, ao combinar modelos de previsão, observações de campo e informações extraídas de dados de sensoriamento remoto e de experimentos em laboratório. (FLORENZANO, 2008, p.12).

O Google Earth (Figura 1) é um programa de visualização de imagens de satélite das mais diversas partes da Terra que disponibiliza um conjunto de ferramentas que permitem realizar mapeamentos, importar e exportar dados; realizar a visualização em 3D, consistindo, portanto em relevante ferramenta a ser explorada para compreensão do relevo. 


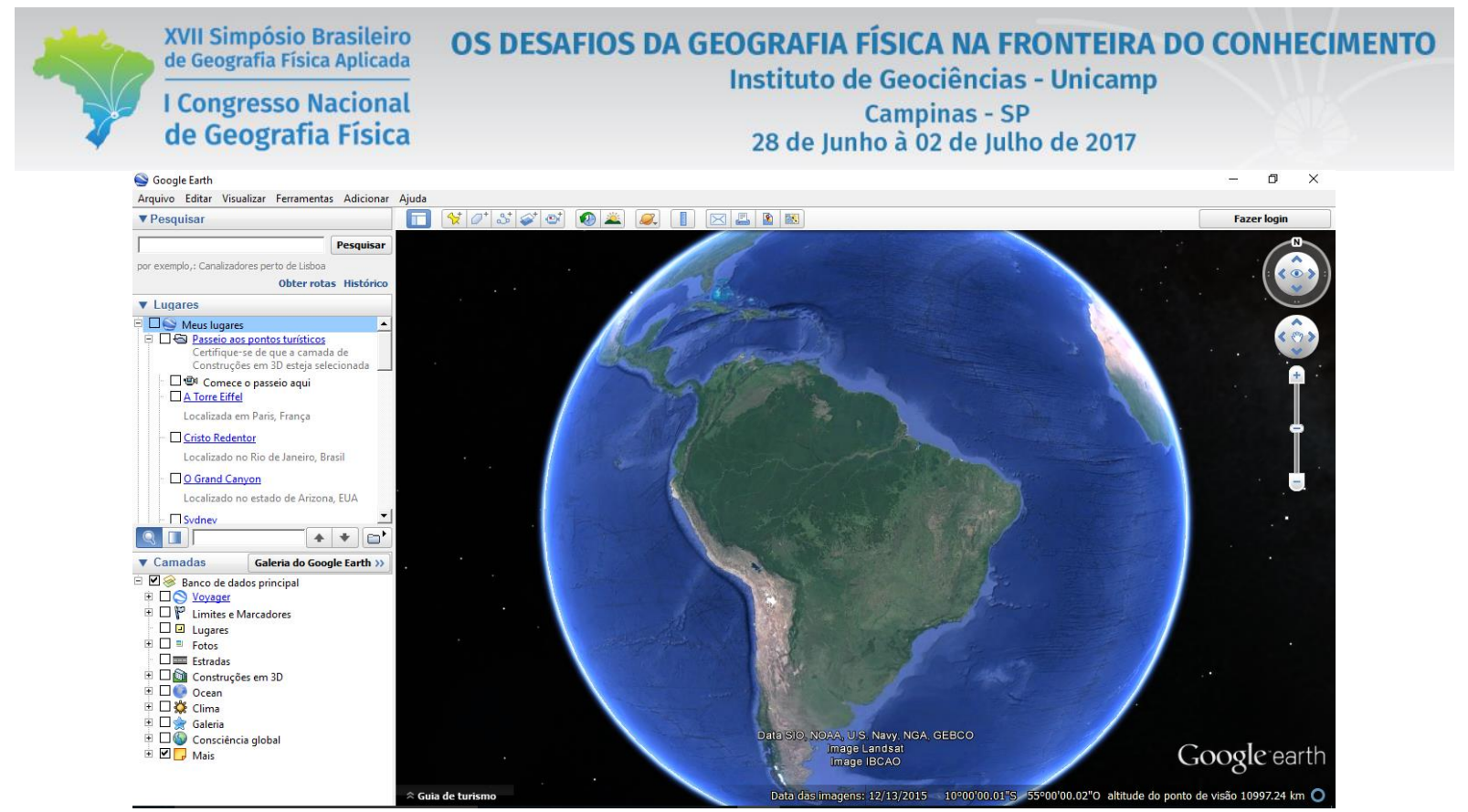

Figura 1: Aspecto do Google Earth. Fonte: Os autores.

O Google Earth possibilita que os usuários insiram informações via internet, criem, editem, importem e enviem informações por meio da linguagem Keyhole Markup Language (.kml). Os dados também podem ser salvos e exportados no formato KMZ (Zipped Keyhole Markup Language), que funciona com uma pasta compactada, na qual são salvos arquivos no formato KML. Este software está acessível para instalação em computadores, smartphones e tablets.

A interface do Google Earth disponibiliza três painéis: Pesquisa, Locais e Camadas. O painel de Pesquisa possibilita a navegação até locais determinados a partir da inserção do nome ou das coordenadas geográficas. O painel Lugares mostra os locais que foram adicionados após a busca ou carregados de fontes externas. Na aba "Camadas", é possível organizar os lugares, linhas e formas e controlar a maneira de visualizar diferentes tipos de informações. Ao ativar e desativar o banco de dados principais o usuário escolhe a camada de seu interesse, podendo visualizar informações que são incluídas por outros usuários, como fotos por exemplo. Em “Opções das Ferramentas” estão disponibilizadas configurações que também podem ser ajustadas ao interesse de quem está navegando. Em um contexto mais específico, as ferramentas oferecidas pelo Google Earth, permitem adicionar pontos, polígonos, marcadores, caminho, mostrarem imagens históricas entre outras funções.

Os controles de navegação (ferramentas de zoom, direção, inclinação) estão no canto superior direito da tela de visualização juntamente com a ferramenta Street View. Este recurso tem diversas potencialidades de uso, pois adiciona dimensionalidade e oferece uma matriz de fotografias e que o usuário tem uma visão em $360^{\circ}$ para muitas cidades, vilas e outros lugares ao redor do mundo. No entanto, quando se trata de estudos geomorfológicos, o uso do Street View fica restrito, pois os lugares com esta função disponível são, em sua maioria, urbanas, e grande parte das paisagens de interesse se encontram fora dessas áreas. 
Considerando o âmbito da ciência geográfica, o Google Earth tem sido utilizado para delimitação de áreas de preservação, análise de paisagens urbanas e sua evolução, planejamento ambiental, reconhecimento de usos da terra, alterações ambientais. No âmbito do ensino e pesquisa o uso do Google Earth não se restringe à Geografia, apesar de mais frequentemente associado a esta. Trabalhos propostos por áreas como na história, literatura, arquitetura, geologia, biologia e diversas outras, tem sido desenvolvido por educadores. Quanto uso do Google Earth para ensino superior no Brasil são raros os trabalhos

Porém, as desvantagens de aplicação do Google Earth, não podem ser negligenciadas. Este tem funcionalidades analíticas e de processamento, reduzidas quando comparado a SIG's como ArcGIS, Quantum GIS, Mapinfo, TerraView, GEOMEDIA, GRASS, gvSIG, SPRING, etc. Oliveira (2010) aborda que o Google Earth é uma ferramenta de visualização que deve ser apresentada com olhar crítico e nesta perspectiva Lima (2012), considera que quando o propósito é visualização das informações, o Google Earth atende bem, mas quanto a aplicações acadêmicas é importante ter um cuidado maior, pois o software não oferece convenções que assegurem padrões de precisão cartográfica e de posicionamento, uma vez que as imagens oferecidas têm níveis de correção variados.

Assim, sem deixar de considerar tais ressalvas, o Google Earth tem sido utilizado em situações que vão além do ensino, em trabalhos de pesquisa de diversas áreas do conhecimento e também tem apresentado relevantes contribuições (Quadro 1). Usando a tecnologia os alunos podem expandir seus conhecimentos e melhorar suas habilidades de pensamento e analítico e podem aplicar aprendizagem para situações apresentadas dentro e fora da sala de aula.

Quadro 1: Vantagens do Google Earth enquanto ferramenta de ensino

\section{Vantagens do Google Earth enquanto ferramenta de ensino}

- interface amigável;

- espera-se, que o tempo gasto para a familiarização com o google earth seja inferior comparado com SIG's;

- instalação gratuita;

- consiste em uma ferramenta de pesquisa;

- integra o estudo de várias disciplinas;

- possibilidade de ser utilizado além dos limites do espaço escolar;

- apresenta relevante quantidade de informações em um contexto geográfico;

- possibilita que os usuários criem e exibam seus dados;

- permite a importação de dados de outros softwares (desde que no formato compatível);

- possui um grande número de usuários que alimentam fóruns de discussão e disponibilizam atividades já realizadas.

- capacitação dos alunos enquanto formadores, posteriormente, enquanto profissionais docentes ou bacharéis, terão habilidades com uso desse software. 
Diversos professores têm incluído nas ementas das disciplinas que lecionam o uso do Google Earth como ferramenta de ensino. Sobre sua experiência com o Google Earth, Dunagan (2007), descreve que este foi incorporado nas atividades de Geomorfologia no laboratório na Universidade do Tennessee juntamente com mapas topográficos. Segundo o professor essa é uma forma altamente visual e de custo eficaz para integrar a tecnologia à geociências. Hanson (2009) também destaca a possibilidade da interface com outros softwares para obtenção de dados do terreno, como mapas topográficos dos EUA, obtidos gratuitamente no Mapfinder. Estes podem ser sobrepostos em camadas com as imagens de satélite do Google Earth. Segundo ele a capacidade de alterar a transparência da camada e alternar entre as imagens facilita a habilidade dos alunos para visualizar a topografia, fazer observações, medir parâmetros das formas do relevo, realizar análises morfométricas. O mesmo reforça também a possibilidade da realização de exercícios em laboratórios ou sala de aula. Assim a combinação de diversas funções permite diferentes usos do Google Earth enquanto ferramenta na disciplina de Geomorfologia (Quadro 2).

Quadro 2: Google Earth enquanto ferramenta de ensino de Geomorfologia.

\section{Usos do Google Earth enquanto ferramenta na disciplina de Geomorfologia}

- como base para pesquisas;

- para apresentações dinâmicas durante as aulas;

- para criar imagens e mapas para o slides e outras ferramentas de apresentação;

- para elaborar mapas de interpretação topográfica;

- na medição: coletar dados quantitativos medindo elevações, distâncias ou áreas;

- na utilização de marcadores e superposições e assim explorar o uso de dados geográficos na tomada de decisões;

- para "viagens de campo" nas diferentes paisagens da Terra;

- visualização de uma área em múltiplas escala;

- mostrar formas de relevo em 3-D;

- coordenadas de latitude e longitude podem ser rapidamente determinada; (5) áreas do mapa pode ser vista de várias perspectivas em 3-D;

- importar mapas topográficos, geológicos;

- para elaboração de atividades participativas e colaborativas.

- os alunos podem navegar casualmente por conta própria ou se envolver em explorações baseadas em indagações estruturados individualmente ou em equipes.

\subsection{O Índice de Hack}

Dentre as diversas possibilidades de aplicação dos conhecimentos geomorfológicos com o Google Earth, foram selecionados os índices morfométricos, que obtidos a partir dos estudos das drenagens fluviais, são entendidos como alternativas pra avaliar os perfis longitudinais dos rios e, assim, obter uma melhor compreensão do processo da evolução do relevo; investigar a interação da tectônica, litologia e fatores climáticos, no âmbito de uma bacia hidrográfica (CHRISTOFOLETTI, 1980). Mais especificamente foi definido o Índice de Hack, que representa a energia e capacidade do curso de água e reflete o simples 
produto da declividade do canal de um ponto determinado e a extensão do canal ao longo da sua extensão superior a partir do ponto demarcado (Hack, 1973). Assim, as ferramentas do Google Earth possibilitam realizaçãod e proceidmentos como: medir comprimento, largura, inclinação, observar a forma do canal; a localização da nascente; altitudes e perfil de elevação.

\section{Materiais e Métodos}

A abordagem realizada neste item busca explorar o uso do Google Earth no contexto das práticas didáticopedagógicas na disciplina de Geomorfologia, e propor a aplicação de uma atividade sem, no entanto, estabelecer um caráter prescritivo, mas sim promover a exploração desta ferramenta, não restringindo às possibilidades aqui retratadas, mas principalmente pretende-se divulgar e promover discussões, estando abertas a intervenções, mudanças, aprimoramentos e a criação de novas propostas ao aplicá-las em situações futuras.

Como proposta de avaliação do Google Earth enquanto instrumento no ensino de Geomorfologia, foi realizada a observação e análise da prática da atividade: Aplicação do Índice de Hack para identificação de setores anômalos e rupturas do relevo.

A elaboração da atividade foi precedida de leitura e análise de textos que tratam do conteúdo, em busda de um embasamento teórico mais consistente, tendo como referências principais: HACK (1973) e CHRISTOFOLETTI (1980). Como área de pesquisa, foi definido o estado de Minas Gerais, por se tratar de uma região que é mais conhecida pelos alunos da disciplina.

Estabelecida esta primeira etapa de definição do tema e embasamento teórico, foi realizada elaboração de um tutorial (RODRIGUES, et. al. 2016), contendo o passo-a-passo para prática da atividade (Figura 2). Este tutorial e a obtenção da base de dados foram organizados pelo docente e monitoras responsáveis pela disciplina, com base no projeto Gis4Geomorphology (2016). Este projeto disponibiliza tutoriais para alunos de pós-graduação em Geociências.

O tratamento e análise dos dados obtidos na prática com o Google Earth foram processados e posteriormente organizados em forma de painel. Para isso, foram utilizados também os softwares Excel e Inkskape. Assim a atividade, enquanto conteúdo da disciplina teve como objetivo compreender a aplicação do Índice de Hack (Relação Declividade/Extensão) para identificar setores de anomalias de drenagem e rupturas de relevo, utilizando softwares como Google Earth, Excel e Inkskape para organizar vários níveis de informações que caracterize um canal fluvial (RODRIGUES, et. al. 2016). 


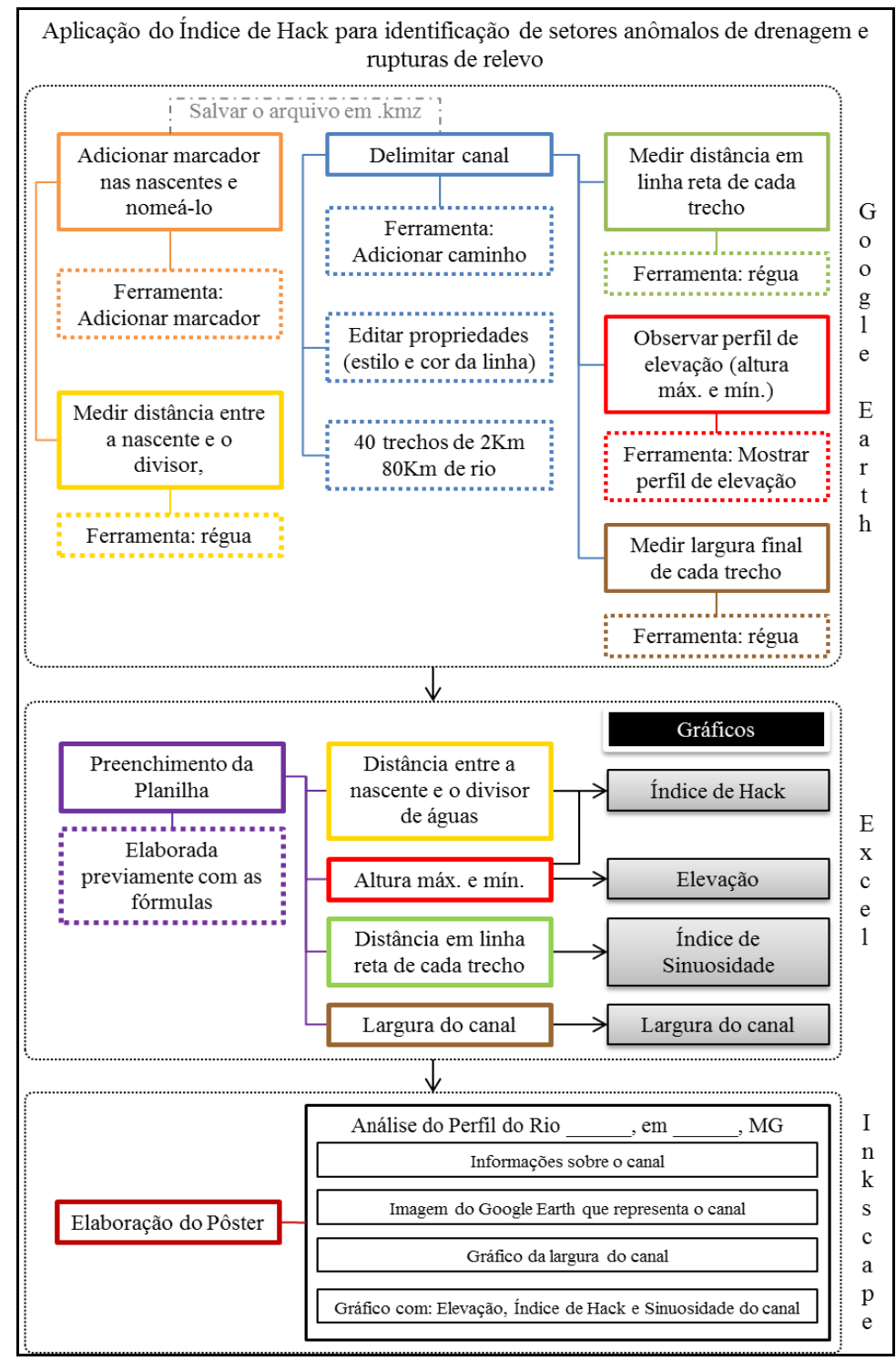

Figura 2: Síntese do tutorial. Fonte: Os autores.

Dentro desse contexto, a prática ficou dividia em três etapas: reconhecimento, delimitação do canal, e obtenção de medidas no GE; preenchimento de dados e construção de gráficos no Excel; interpretação, análise e produção de resultados e pôster no Inkskape. A partir disso, foi possível observar de maneira crítica os resultados do trabalho desenvolvido e, dessa maneira, obter subsídios para buscar um aprimoramento.

Sobre os procedimentos metodológicos da aplicação da atividade, foram estabelecidos os seguintes: obtenção da base hidrográfica de todos os rios de Minas Gerais, e criação do arquivo .kmz com 80 pontos em nascentes, determinando como condição, rios com pelo menos $80 \mathrm{~km}$ de extensão. Cada aluno ficou responsável por um rio, e esta distribuição foi realizada por meio de sorteio. 
Então, para que os alunos iniciassem a realização da atividade foram necessários os seguintes instrumentos: arquivo $\mathrm{kmz}$ com ponto marcando a nascente do rio; arquivo Excel com fórmulas; laboratório de informática com pelo menos 1 computador por aluno; softwares instalados: Google Earth, Excel e Inkskape; e conexão com a internet de boa qualidade.

É relevante destacar que o índice de Hack não foi definido apenas com as informações de "Altura máxima e mínima" e a "Distância entre a nascente e o divisor de águas". O arquivo no formato Excel, disponibilizado para os alunos, foi previamente organizado com dados e fórmulas necessárias para obter o Índice de Hack, um gráfico que representava o Índice de Sinuosidade, e um gráfico com a largura do canal.

Considera-se ainda a atividade foi aplicada no âmbito da disciplina de Geomorfologia pressupõe-se que houve o acompanhamento do professor, a introdução acerca do assunto abordado e a posterior correção e discussão da atividade e também que existem textos de referência acessíveis para realização da mesma.

\section{Resultados e discussões}

A atividade desenvolvida está relacionada a conteúdos e habilidades próprios da Geomorfologia, mas não se resume a esta. Competências oriundas da Cartografia e Sensoriamento Remoto também são relevantes. O uso das ferramentas do Google Earth possibilitou avançar na compreensão dos aspectos geomorfológicos de uma bacia hidrográfica. O Quadro 3 explicita a atividade proposta sugerindo alternativas de trabalho a partir da descrição dos objetivos almejados.

Quadro3: Atividade Índice de Hack: proposta de trabalho.

\begin{tabular}{|c|c|}
\hline Objetivos & Como alcançar \\
\hline $\begin{array}{l}\text { Identificar, compreender e reconhecer as diferentes fisiografias fluviais e } \\
\text { sua relação com o relevo. }\end{array}$ & \multirow{4}{*}{$\begin{array}{l}\text { Visualização, observação, avaliação e } \\
\text { digitalização do canal no Google Earth. }\end{array}$} \\
\hline $\begin{array}{l}\text { Analisar os perfis longitudinais dos rios, a partir da relação entre a } \\
\text { altimetria e a distância da nascente. }\end{array}$ & \\
\hline $\begin{array}{l}\text { Observar a relevância do embasamento rochoso na distribuição da } \\
\text { topografia no processo de evolução do relevo em uma determinada } \\
\text { paisagem. }\end{array}$ & \\
\hline $\begin{array}{l}\text { Compreender o papel erosivo dos canais fluviais (largura, inclinação, } \\
\text { forma). }\end{array}$ & \\
\hline Identificar setores de anomalias de drenagem e rupturas de relevo. & $\begin{array}{l}\text { Visualização, observação, avaliação e } \\
\text { digitalização do canal no Google Earth. } \\
\text { Compilação e tratamento dos dados. }\end{array}$ \\
\hline
\end{tabular}

Fonte: Os autores.

Dos alunos que realizaram a atividade (69 alunos) apenas 1 aluno ainda não havia utilizado o Google Earth, segundo ele por não ter verificado a necessidade. Sobre os equipamentos utilizados para navegar no 
Google Earth (considerando que os alunos poderiam ter utilizado mais de um equipamento), 96\% dos alunos o fizeram em computador, 27\% em smartphone, e 7\% já fizeram uso do Google Earth em tablets.

Após a realização da atividade, foi aplicado um novo questionário, com intuito de avaliar a prática e assim realizar os ajustes necessários para a divulgação e nova aplicação da mesma. Quanto ao nível de dificuldade $71 \%$ consideram médio, $25 \%$ baixo e $4 \%$ alto. $88 \%$ acreditaram que o Google Earth contribuiu para o melhor aprendizado, $8 \%$ não souberam opinar e $4 \%$ não consideram que o Google Earth contribuiu.

Os alunos também escreveram como o Google Earth contribuiu para o aprendizado na disciplina de Geomorfologia. Os argumentos citados pelos alunos foram: possibilidade de ter uma visão espacial de lugares; analisar o relevo mesmo estando distante; relacionar a teoria estudada em sala com a realidade; as ferramentas contribuíram para melhor compreensão das características dos rios; possibilita um “encurtamento" das distâncias (“o mundo fica pequeno"); e facilita o entendimento.

Porém alguns alunos apontaram que, realizaram a atividade de maneira mecânica, apenas repetindo o que estava no tutorial, outros descreveram ainda que a atividade foi extensa e trabalhosa. Um aluno apontou como dificuldade de visualização de algumas áreas, por conta da resolução das imagens ou presença de nuvens. Outra ressalva apontada pelos alunos foi que na maior parte dos procedimentos foi necessária a repetição, principalmente a digitalização do canal. Nesse aspecto verificou-se a necessidade de reformulação no tutorial, pois os alunos tiveram dificuldades em salvar o arquivo de maneira correta.

Sobre a realização das etapas do trabalho, cerca de $25 \%$ dos alunos não entregaram o trabalho completo, justificando a ausência de tempo para conclusão ou dificuldades de elaboração dos gráficos no software Excel (última etapa do trabalho), sendo que alguns deles sugeriram que esta etapa fosse descrita de maneira mais detalhada e outros sugeriram ainda que além, do Excel, também fosse acrescentado no tutorial o passo-a-passo para elaborar os gráficos no software LibreOffice, uma vez que não tinham acesso ao Excel.

Diante da análise do nível de complexidade das etapas de realização do trabalho constatou-se que os alunos consideraram os comandos realizados no Google Earth complexidade baixa a média. O procedimento de digitalizar o canal e determinar a sua largura foram considerados pelos alunos como de média dificuldade. Esses são procedimentos simples do ponto de vista operacional, mas que exigem dos alunos habilidades que vão além do manuseio das ferramentas do Google Earth, pois para realizá-los foi necessária a interpretação e análise das imagens de satélite. As etapas consideradas mais complexas pelos alunos foram a elaboração dos gráficos e do pôster, ambas realizadas em outros softwares (Grafico 1). 


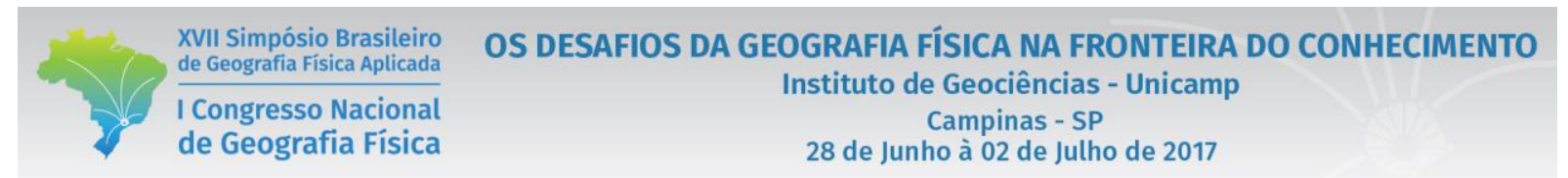

Gráfico 1: Avaliação da dificuldade em realizar os trabalhos.

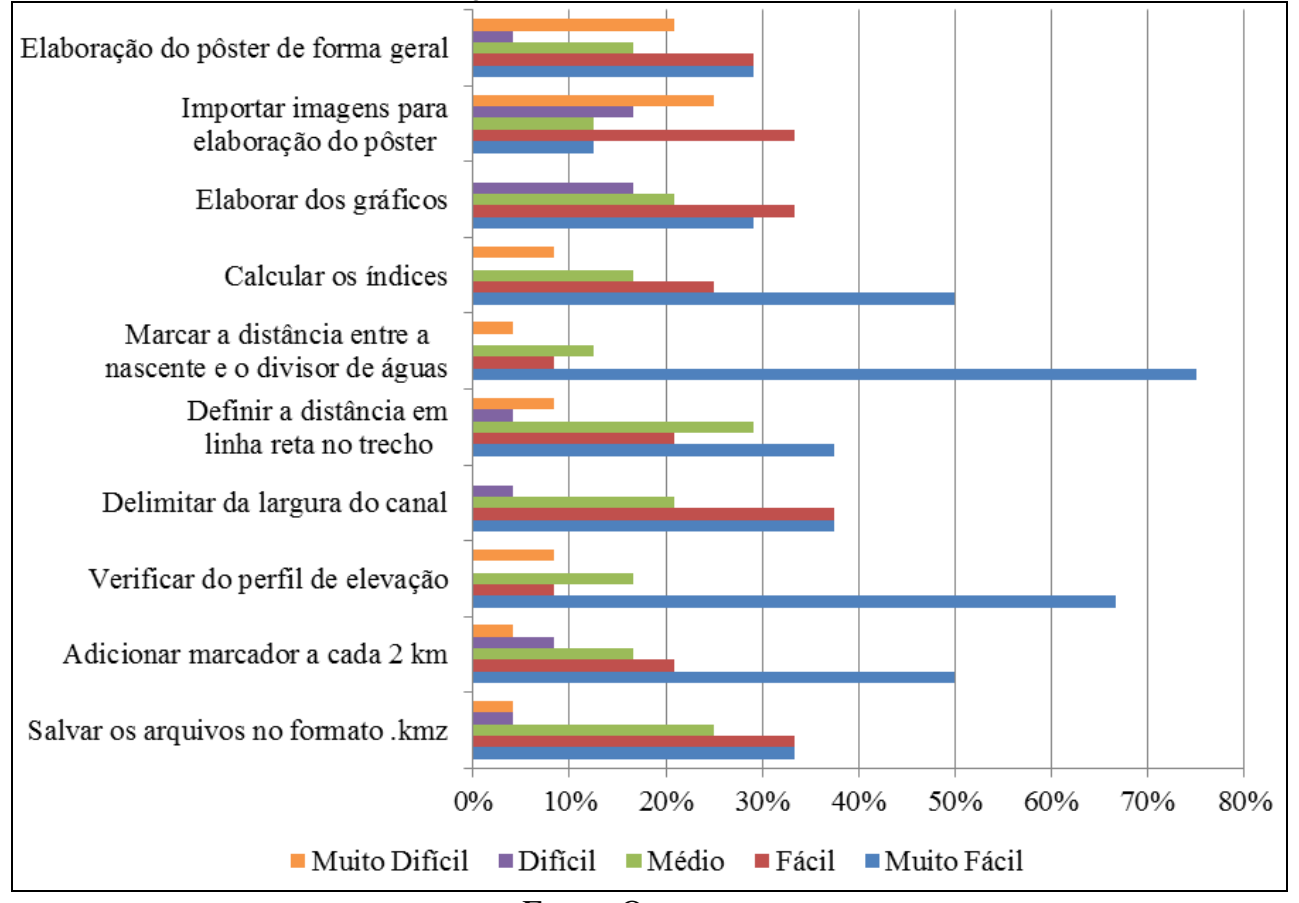

Fonte: Os autores.

A avaliação da atividade foi realizada pelo professor da disciplina que atribuiu os pontos de acordo com a realização ou não de procedimentos, bem como a precisão e o resultado dos mesmos. No presente trabalho, considerou-se somente a análise das dificuldades e habilidades desenvolvidas pelos alunos para realização da atividade, independente da pontuação final obtida pelos alunos.

No que se refere aos procedimentos realizados no Google Earth, os erros mais frequentes foram observados na qualidade na digitalização do canal, apresentando erros de precisão, ou seja, alguns alunos não aproximaram a altitude do ponto e visão de forma suficiente a proporcionar o delineamento do rio de maneira correta (33\% dos alunos); ou digitalização sem definição, uma vez que $29 \%$ dos alunos apresentaram erros interpretação da imagem, principalmente em trechos em que o rio não ficava explícito como em áreas de vereda, com intensa mata ciliar ou coberto por nuvens. Quanto à possibilidade de minimizar tais erros, algumas alternativas podem ser propostas como, por exemplo: estabelecer um padrão na altitude do ponto de visão, para que o aluno possa realizar o trabalho de maneira não muito morosa, mas também sem negligenciar o curso do rio. Outra possibilidade é utilizar a ferramenta de imagens históricas e assim é possível que em anos anteriores consiga obter uma melhor visualização. Quanto ao preenchimento e elaboração dos dados na planilha, $21 \%$ dos alunos não fizeram os gráficos, etapa que relataram ter tido maior dificuldade. Na etapa de elaboração do pôster (Figura 3), as principais falhas naturalmente são resultado das cometidas nas etapas anteriores, e dessa forma parte dos pôsteres estavam incompletos. Foram identificados ainda erros na edição e estruturação (29\% dos alunos). 


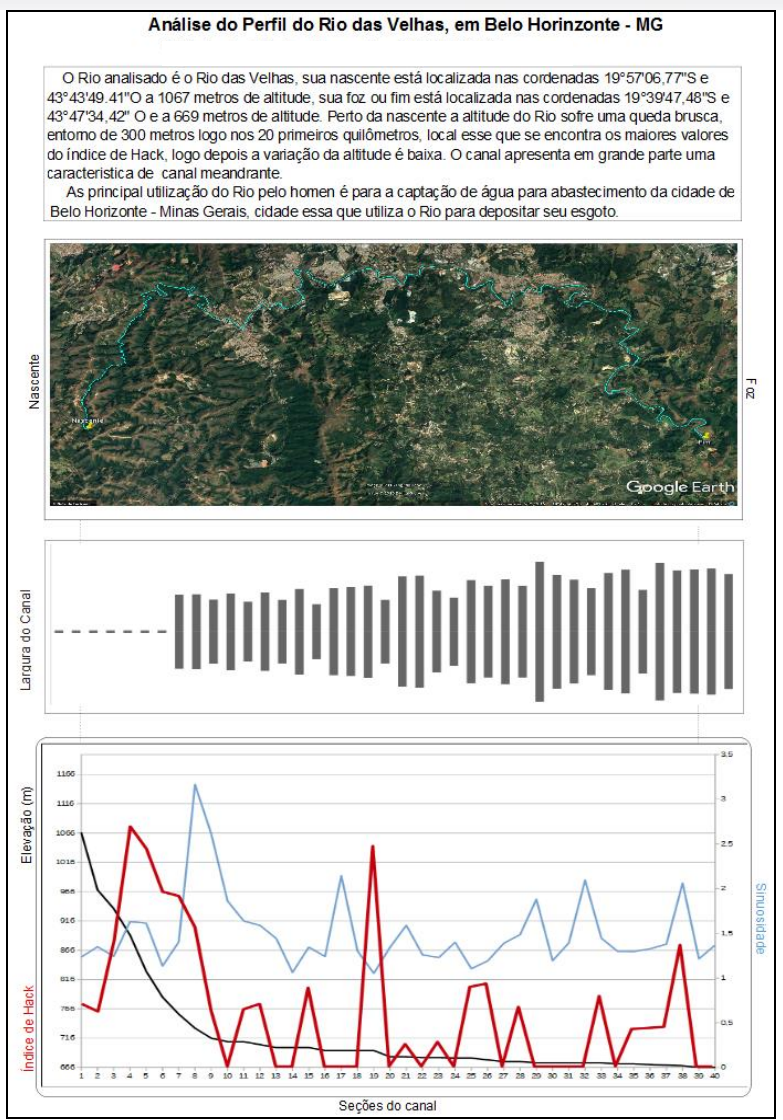

Figura 3: Exemplo de resultados: Pôster de um aluno da disciplina. Fonte: Rodrigues et. al. (2016)

\section{Considerações finais}

A elaboração de atividades, com intencionalidade, em busca do ensino mais eficiente no âmbito dos saberes geomorfológicos não é uma tarefa fácil. É preciso ressaltar que a aprendizagem dos sujeitos acontece de modos e em tempos diferenciados, consistindo esse mais um grande desafio para o professor. Algumas percepções ficaram evidentes ao longo da execução da atividade no laboratório de informática: é essencial a presença do professor ou monitor para que fossem esclarecidas as dúvidas, ou que seja destinado um canal de comunicação para tal; seria interessante um treinamento prévio com noções básicas de interpretação de imagens de satélite, ou que já tivesse cursado a disciplina de Sensoriamento Remoto ou afim; o planejamento prévio é fundamental, inclusive com a realização de testes; o interesse dos alunos configura parte essencial; avaliação do tempo necessário para realização da atividade; os alunos precisam de uma referência para consulta tanto quanto a teoria que está sendo aplicada, como para auxílio no uso dos softwares; é valorosa a possibilidade de os alunos visualizarem por meio da prática os conteúdos descritos em textos; realização de um feed back, junto aos alunos após a conclusão da atividade. Assim, a 
elaboração e aplicação de tais atividades exige uma percepção das necessidades de cada realidade e a constante atualização dos procedimentos em busca de atingir os melhores resultados.

Dentro desta perspectiva, constatou-se que a atividade permitiu uma maior participação e interação dos alunos, monitoras e professor, constituindo-se signficativo procedimento de construção da aprendizagem. Além disso, diante da avaliação dos trabalhos dos alunos e do questionário respondido pelos mesmos, o Google Earth, apresenta-se como relevante alternativa para desenvolvimento de práticas de ensino de Geomorfologia.

\section{Referências}

AFONSO, A. E. Perspectivas e possibilidades do ensino e da aprendizagem em Geografia Física na formação de professores. Rio de Janeiro. Tese de Doutorado (Geografia) - PPGG - UFRJ. 2015. 237p.

BERTOLINI, W. Z. O ensino do Relevo: Noções e propostas para uma didática da Geomorfologia. 2010. $124 \mathrm{f}$. Dissertação de Mestrado. Programa de Pós-Graduação do Departamento de Geografia da Universidade Federal de Minas Gerais.

CHRISTOFOLETTI, A. Geomorfologia. 2ª Ed. São Paulo: Blucher, 1980.

DUNAGAN, S. Integrating Google Earth with geomorphology lab activities and student presentations. 2007 GSA Denver Annual Meeting (28-31 October 2007) Paper No. 56-2, 2007.

HACK, J. T. Stream-profile analysis and stream-gradient index. Journal of Research of the United States Geological Survey, v. 1, n. 4, p. 421-429, 1973.

HANSON, L.S. Google Earth and Free Image Processing Software into Geomorphology Labs: Geological Society of America Abstracts with Programs, Vol. 41, No. 3, p. 13, 2009.

FLOREZANO, T.G. Introdução à Geomorfologia. In: Geomorfologia - Conceitos e Tecnologias Atuais. Oficina de Textos, São Paulo, 318p. 2008. P.11-30

LIMA, R.de S. Google Earth aplicado a pesquisa e ensino da Geomorfologia. In: Revista de Ensino de Geografia, Uberlândia, v. 3, n. 5, p. 17-30, jul./dez. 2012.

MORAN, José Manuel et al. Novas tecnologias e mediação pedagógica. 14. ed. Campinas, SP: Papirus, 2000.

OKADA, A. L. Mapas Conceituais em projetos e atividades pedagógicas. In: MORAES, U. C. Tecnologia educacional e aprendizagem: o uso dos recursos digitais. São Paulo: Livro Pronto, 2007. p. 115 - 127.

OLIVEIRA, A. S. Contribuição Teórico-Metodológica para o Ensino de Geomorfologia. 2010. 306 f. Tese de Doutorado. Universidade Estadual Paulista, Faculdade de Ciências e Tecnologia. Presidente Prudente. 2010.

RODRIGUES et. al. (2016). Tutorial Análise de Canal Fluvial: índice de Hack. Disponível em: <https://www.researchgate.net/publication/314857152_Tutorial_Analise_de_Canal_Fluvial_-_Indice_de_Hack>. Acesso em: 13 de Março. 2017.

SOUZA, C. J. de O. Geomorfologia no ensino superior: difícil, mas interessante! Por quê? Uma discussão a partir dos conhecimentos e das dificuldades entre graduandos de geografia - IGC/UFMG. 2009. $264 \mathrm{f}$. Tese de Doutorado. Departamento de Geografia da UFMG, Belo Horizonte, 2009.

Agradecimentos

À Fundação de Amparo à Pesquisa do Estado de Minas Gerais (FAPEMIG) pelo apoio financeiro na participação no XVII Simpósio Brasileiro de Geografia Física Aplicada. Campinas SP, 2017. 